\title{
Evaluation of Materials for the Separation of Germanium from Gallium, Zinc and Cobalt
}

Jonathan Fitzsimmons ${ }^{*}$ and Leonard Mausner

Medical Isotope Research \& Production Program, Collider-Accelerator Department, Brookhaven National Laboratory, NY 11973, USA

\begin{abstract}
In the past ${ }^{68} \mathrm{Ge}$ (Germanium-68) was purified with toxic organic solvents in liquid-liquid extractions making the product unacceptable by the FDA (food and drug Administration) for human use. The authors report initial studies utilizing three or four columns consisting of sequences of AG1, AG50, Chelex 100 and/or Sephadex G25 resins. Five purification methods were examined and a separation consisting of the sequence: AG1-Chelex100-Sephedex G25 provided 87\% recovery of germanium. Fractionation of the elution resulted in high germanium concentrations.
\end{abstract}

Key words: ${ }^{68} \mathrm{Ga},{ }^{68} \mathrm{Ge}$, Sephadex $\mathrm{G} 25$, radiochemical separation.

\section{Introduction}

PET (positron emission tomography) with peptides radiolabeled with ${ }^{68} \mathrm{Ga}$ (Gallium-68) is emerging as a suitable method for the diagnosis of disease and evaluating treatments $[1,2] .{ }^{68} \mathrm{Ga}$ has a short half-life $\left(\mathrm{T}_{1 / 2}=68.1 \mathrm{~min}\right)$ and is formed from the electron capture of ${ }^{68} \mathrm{Ge}$ (Germanium-68) which has a longer half-life $\left(T_{1 / 2}=271\right.$ days $)$. This isotope pair has been used in PET calibration sources as well as the development and marketing of the germanium/gallium medical isotope generator. During production of ${ }^{68} \mathrm{Ge}$ the following isotopes are coproduced: ${ }^{65} \mathrm{Zn}$ (Zinc-65), $T_{1 / 2}=244$ days and trace quantities of radioactive cobalt. To isolate ${ }^{68} \mathrm{Ge}$ from the Gallium target material a two-step process is used which involves leaching ${ }^{68} \mathrm{Ge}$ from natural gallium. Followed by liquid/liquid solvent extractions performed with various concentrations of $\mathrm{HCl}$ and toluene or carbon tetrachloride [3]. The toxic organics are class 1 and 2 solvents according to the FDA (food and drug Administration) and should be avoided when preparing a drug substance $[4,5]$.

Ideally the purification of Ge should use aqueous chemistry to remove all the $\mathrm{Zn}$ and Co, but leave part

\footnotetext{
"Corresponding author: Jonathan Fitzsimmons, Ph.D., research field: radiochemistry.
}

per million levels or less of natural Ga. In the solvent extraction approach ${ }^{68} \mathrm{Ge}$ recovery yields are $85 \%$ with greater than $99 \%$ radiopurity with average activity concentrations of $92.96 \mathrm{mCi} / \mathrm{mL}$ [6]. The separation should produce ${ }^{68} \mathrm{Ge}$ with greater than $80 \%$ recovery and the final product needs to be in $0.1 \mathrm{M}$ $\mathrm{HCl}$ with a radiochemical concentration greater than $50 \mathrm{mCi} / \mathrm{mL}$. Volume reduction of the $\mathrm{Ge} / \mathrm{HCl}$ solution to meet the activity concentration requirement is not practical as $\mathrm{Ge}$ and $\mathrm{Ga}$ tetrachloride are both extremely volatile, and would result in loss of product and a contamination issue $[7,8]$. These requirements for the ${ }^{68} \mathrm{Ge}$ product make purification of Gefrom gallium metal challenging.

The studies herein evaluate the retention of $\mathrm{Ge}, \mathrm{Ga}$, Co and $\mathrm{Zn}$ on Chelex 100 and Sephadex G25 from alkaline solution. This knowledge was used to investigate five different separation approaches to separate Ge utilizing multiple resin sequences. These initial studies focus on a separation that utilizes the leaching step followed by column chromatography.

\section{Materials and Methods}

\subsection{Materials}

All solutions were prepared with $18 \mathrm{M} \Omega$ Millipore water, $\mathrm{pH}$ adjustments were checked with $\mathrm{pH}$ strips 
(EMD chemicals). Coarse, fine and medium mesh Sephadex G25 was purchased from Phamcea, and Econo-Pac columns, analytical grade AG1X8, AG50, and Chelex 100 resins were purchased from BIO-RAD. ICP-MS (inductively coupled plasma-mass spectrometry) standards for $\mathrm{Ga}, \mathrm{Ge}, \mathrm{Co}, \mathrm{Zn}$, a 19 element mixed standard were purchased from SPEX CertiPrep (Metuchen, NJ) and were used to prepare a set of ICP calibration and QC (quality control) standards. Gallium metal and other chemical were purchased from Sigma Aldrich. All other materials were purchased from Fisher Scientific.

\subsection{Single Column Studies}

\subsubsection{Sephadex Procedure}

A solution contining $100 \mu \mathrm{g}$ of $\mathrm{Ga}, \mathrm{Zn}$ and Ge was prepared from the ICP standards and the solution was adjusted to $\mathrm{pH} 13.0$ with $10 \mathrm{M} \mathrm{NaOH}$. Then the solution was loaded onto a Sephadex G25 (fine or coarse) column, and the column was rinsed with 2-5 bed volumes of $0.1 \mathrm{M} \mathrm{NaOH}$, then 1-2 bed volumes of water. The Ge was eluted with $0.1 \mathrm{M} \mathrm{HCl}$ and the elutions were fractionated. The separation was repeated with a solution containing $\mathrm{Ga}, \mathrm{Ga}$ and $\mathrm{Co}$.

\subsubsection{Chelex 100}

A solution containing $100 \mu \mathrm{g}$ of $\mathrm{Ga}, \mathrm{Zn}, \mathrm{Co}$ and $\mathrm{Ge}$ was prepared from the ICP standards and the solution was adjusted to $\mathrm{pH} 14.0$ with $10 \mathrm{M} \mathrm{NaOH}$. The solution was loaded onto a Chelex 100 column, and the column was rinsed with $2-5$ bed volumes of $1.0 \mathrm{M}$ $\mathrm{NaOH}$, then 1-2 bed volumes of water. The retained metals were eluted with $0.1 \mathrm{M} \mathrm{HCl}$ and the elutions were fractionated.

\subsection{Multi-Column Separations}

\subsubsection{Gallium Stock Solution}

A $0.14 \mathrm{~g} / \mathrm{mL}$ gallium stock solution in $4 \mathrm{M} \mathrm{HCl}$ was prepared [9].

\subsubsection{Working Metal Solution}

To a beaker was added $0.5 \mathrm{~mL}$ of $1,000 \mu \mathrm{g} / \mathrm{mL}$ of $\mathrm{Zn}$ and Co ICP standards and the beaker was heated to dryness. To the beaker was added 3-7.143 $\mathrm{mL}$ of the gallium solution (0.5-1 grams) and $1 \mathrm{~mL}$ of 604 $\mu \mathrm{g} / \mathrm{mL}$ Germanium in $0.05 \mathrm{M} \mathrm{HCl}$. The solution was diluted to $20 \mathrm{~mL}$ with $4 \mathrm{M} \mathrm{HCl}$. This solution represents the leached amount of $\mathrm{Ga}, \mathrm{Ge} \mathrm{Zn}$ and $\mathrm{CO}$ from an irradiated gallium target and was prepared and used for methods 1-5.

2.3.3 Separation Studies

A flow chart and column conditions that summarize the different separation methods are illustrated in Fig. 1 and Table 1. AG1X8, Chelex 100 and medium Sephadex resins were prepared in Econo-Pac columns, and the AG50 column was prepared in poly-prep column. Briefly, in methods 1-5 twenty mL's of the metal solution was diluted to $1.6 \mathrm{M} \mathrm{HCl}$ and an AG1 column was used to remove $\mathrm{Zn}$. Next $10 \mathrm{M} \mathrm{NaOH}$ was added to the solution to neutralize the acid and generate a solution at a $\mathrm{pH}$ of 14 , which was checked by $\mathrm{pH}$ paper. The sequence of columns used in methods 1-5 was: Method 1: [AG1, ( $\mathrm{NaCl}$ spike), Sephadex G25, AG50]. After the $\mathrm{AG} 1$ column $\mathrm{NaCl}$ was added to the basic metal solution to generate a $1 \mathrm{M} \mathrm{NaCl}$, the $\mathrm{pH}$ adjusted to 14.0 and the solution stirred until dissolved. Method 2: [AG1, Chelex 100, Sephadex G25]. Method 3: [AG1, ( $\mathrm{NaCl}$ spike) Chelex 100, Sephadex G25]. Method 2 was used with the exception that the eluted solution from the AG1 column was added to $\mathrm{NaOH}$ and $\mathrm{NaCl}$ to make a $1 \mathrm{M} \mathrm{NaOH}$ and $1 \mathrm{M} \mathrm{NaCl}$ solution prior to adding the solution to the Chelex 100 column. Method 4: [AG1, Chelex 100, ( $\mathrm{NaCl}$ spike) Sephadex G25]. Method 2 was used with the exception that the eluted solution from the Chelex 100 column was added to $\mathrm{NaCl}$ to make a $1 \mathrm{M} \mathrm{NaCl}$ solution prior to adding the solution to the Sephadex G25 column. Method 5: [AG1, Chelex 100 ( $\mathrm{NaCl}$ spike) Sephadex G25, AG50]. Method 4 was used with the exception that the $\mathrm{HCl}$ eluted from the Sephadex G-25 column was passed through an AG 50 column.

\subsection{Analysis}

Stable metals analysis of the final $\mathrm{HCl}$ elutions was 


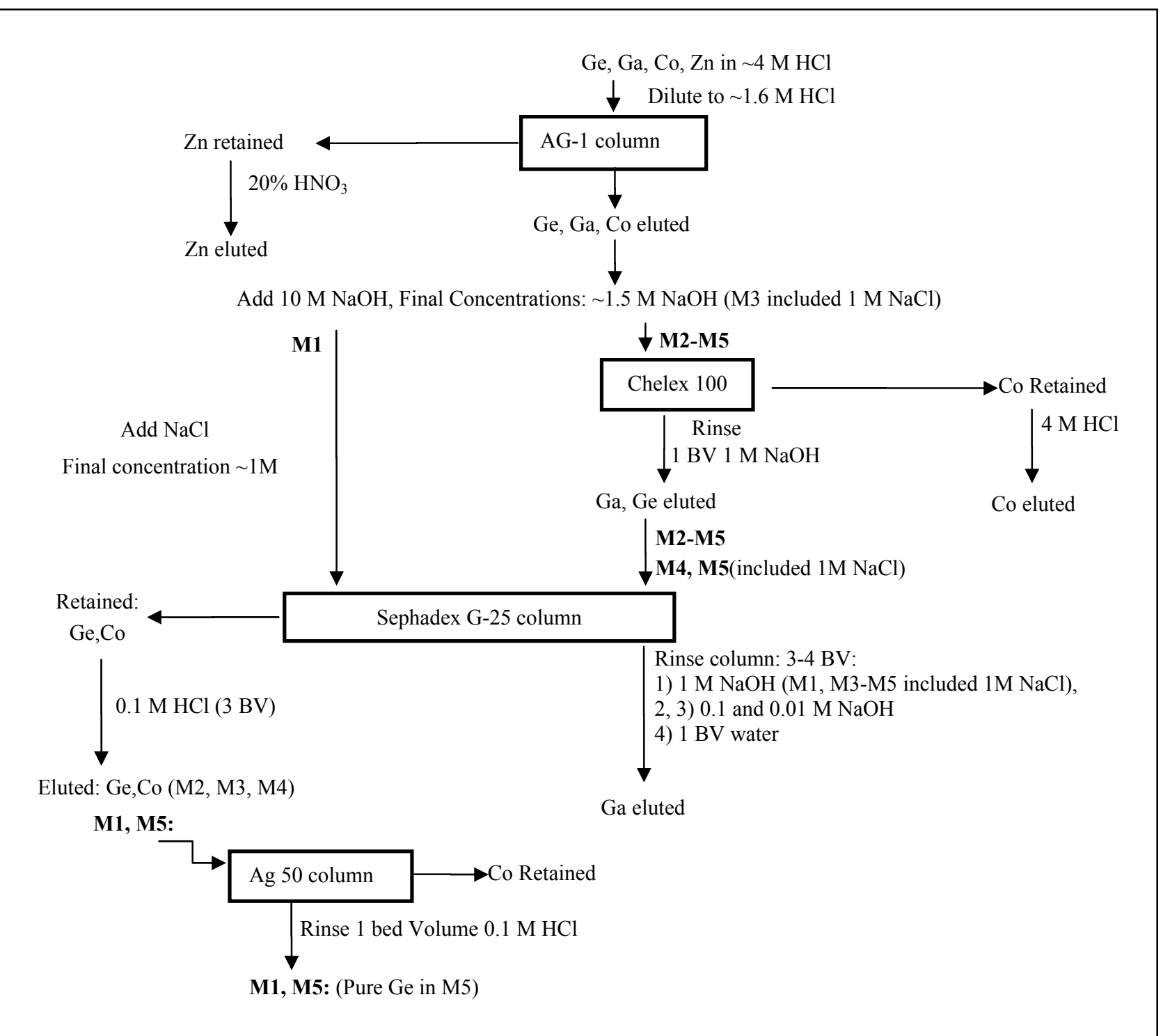

Fig. 1 Flow chart for separation methods 1-5. $\mathrm{MX}=$ method $\mathrm{x} . \mathrm{BV}=$ bed volumes.

Table 1 Properties of different columns used in the different methods. a = time needed to elute the load solution.

\begin{tabular}{lllll}
\hline Resin & $\begin{array}{l}\text { Mass } \\
(\mathrm{g})\end{array}$ & $\begin{array}{l}\mathrm{BV} \\
(\mathrm{mL})\end{array}$ & Retained & Eluted \\
\hline AG1X8 & 1.5 & 3 & $\mathrm{Zn}$ & $\mathrm{Ga}, \mathrm{Ge}, \mathrm{Co}$ \\
Chelex 100 & 3.5 & 5 & $\mathrm{Co}$ & $\mathrm{Ga}, \mathrm{Ga}$ \\
Sephadex G25 & 0.8 & 4 & $\mathrm{Ge}, \mathrm{Co}$ & $\mathrm{Ga}$ \\
AG50 & 0.5 & 1 & $\mathrm{Co}$ & $\mathrm{Ge}$ \\
\hline
\end{tabular}

performed using Optima 2000 ICP-OES (inductively coupled plasma-optical emission spectroscopy) unit (Perkin Elmer) with plasma operated at 1,300 W and samples were prepared in $2 \%$ nitric acid. A standard curve was prepared from a 19 element standard containing $\mathrm{Cu}, \mathrm{Pb}, \mathrm{Zn}, \mathrm{Co}, \mathrm{Cr}, \mathrm{Cd}, \mathrm{Ni}, \mathrm{Fe}, \mathrm{Mn}, \mathrm{Al}, \mathrm{Ga}$,
$\mathrm{Ge}, \mathrm{Sr}, \mathrm{Be}, \mathrm{Mg}, \mathrm{Rb}, \mathrm{Ca}, \mathrm{Ba}$, and $\mathrm{Nb}$ at concentrations from $0.05-10 \mathrm{ppm}$. For the single column studies the amount of $\mathrm{Co}, \mathrm{Ga}, \mathrm{Ge}$, and $\mathrm{Zn}$ was determined in the eluted load solution, $\mathrm{NaOH}$ rinses, water rinse and the $\mathrm{HCl}$. In each method ICP-OES samples were prepared from diluted samples of: the eluted water ( 1 bed 
volume $)$ and the fractionated $(6 \times 2 \mathrm{~mL}) 0.1 \mathrm{M} \mathrm{HCl}$ elutions. In the five methods the mass of each metal was determined in each $2 \mathrm{~mL} \mathrm{HCl}$ fraction, the masses summed for the $\mathrm{HCl}$ fractions, and the concentration determined for the entire $\mathrm{HCl}$ elution $(12 \mathrm{~mL})$.

\section{Results and Discussion}

The evaluation of Sephadex G25 resin for Ge purification was based on research where $\mathrm{Ge}$ was purified from rocks [10]. Attempts to perform the separation with a Sephadex column at $\mathrm{pH}$ values below 13.0, as described in the literature, resulted in the slow formation of a white insoluble solid that stopped column flow. ICP-OES analysis of the insoluble species indicated the presence of both gallium and germanium. At values above $\mathrm{pH} 10 \mathrm{Ga}$ speciation diagrams indicate $\mathrm{Ga}$ is present in the form of $\mathrm{Ga}(\mathrm{OH})_{4}{ }^{-}$and insoluble $\mathrm{Ga}(\mathrm{OH})_{3}$ which was the cause of the insoluble $\mathrm{Ga}$ [11]. Ge speciation diagrams indicate $\mathrm{Ge}$ is present in the form of the soluble species $\mathrm{GeO}(\mathrm{OH})_{3}{ }^{-}$and $\mathrm{GeO} 2(\mathrm{OH})_{2}{ }^{2-}$ [9]. As a consequence of insoluble metal hydroxides at $\mathrm{pH}$ values between 10 and 13, high concentration of hydroxide was needed to form complexes of soluble metal hydroxides and the separations were performed at $\mathrm{pH} 14$.

\subsection{Single Column Studies}

Table 2 summarizes the single column studies with Sephadex G25 and Chelex 100. Briefly, in the Sephadex G25 studies the amount of $\mathrm{Ga}$ in the elutedload and rinse solution was $98 \%$ and the $\mathrm{HCl}$ elutions contained: $91.5 \%$ of the $\mathrm{Ge}, 13 \%$ of $\mathrm{Zn}$ and > $95 \%$ of Co. Single column studies with Sephadex indicated $\mathrm{Ge}$ and $\mathrm{Co}$ behave similar with very high retention on the resin; in contrast, Ga has minimal retention on Sephadex. Only $80 \%$ of $\mathrm{Zn}$ was removed utilizing the Sephadex. Clearly the approach with Sephadex would require more than one column and Chelex 100 was analyzed for its ability to remove Co and $\mathrm{Zn}$. In a single column study the Chelex 100 retained $91 \%$ of the Co and $18 \%$ of the $\mathrm{Zn}$ while $>95 \%$ of the $\mathrm{Ge}$ and $\mathrm{Ga}$ were eluted in the load and rinse steps. Separation attempts with Bio Rad 501 resin with $\mathrm{Ga} / \mathrm{Ge} / \mathrm{Co} / \mathrm{Zn}$ in $0.1 \mathrm{M} \mathrm{HCl}$ resulted in mixed results with $43-70 \%$ of the metals being eluted, and in a similar separation with $1 \mathrm{M} \mathrm{NaOH}>95 \%$ of $\mathrm{Ga}, \mathrm{Ge}$, and Co were eluted in the load and washings along with $76 \%$ of $\mathrm{Zn}$. A one or two column method with $\mathrm{NaOH} / \mathrm{NaCl}$ approach will not separate $\mathrm{Co}$ and $\mathrm{Zn}$ from Ge. From these initial studies a three column purification approach was evaluated where $\mathrm{Zn}$ was removed first by an AG1 column [12], and Co is removed by either Chelex 100 and/or AG50, and a Sephadex G25 column is used for the separation of Ga from Ge.

\subsection{Multicolum Studies}

Table 2 illustrates the differences of the methods and compares the characteristics of the final product (12 $\mathrm{mL}$ of the $0.1 \mathrm{M} \mathrm{HCl}$ elutions) of methods $1-5$ to the current organic extraction method [6]. The

Table 3 The percent Ga, Ge, $\mathrm{Zn}$, and Co recovered in the rinse steps and the HCl elutions in single column studies.

\begin{tabular}{lcccc}
\hline & \multicolumn{4}{c}{ Percent } \\
\cline { 2 - 5 } & $\mathrm{Ga}$ & $\mathrm{Ge}$ & $\mathrm{Zn}$ & $\mathrm{Co}$ \\
\hline Sephadex G25 & 98 & 6.2 & 70 & 0.4 \\
Eluted in load, NaOH rinses & 0.0 & 0.0 & 8.0 & 0.0 \\
Water & 2.3 & 92 & 14 & 99 \\
Eluted in HCl & & & 81 & 8.6 \\
Chelex 100 & 99 & 97 & 1.5 & 0.1 \\
Load and NaOH rinse & 0.2 & 0.5 & 18 & 91 \\
Water rinse & 0.3 & 2.8 & & \\
$0.1 \mathrm{M} \mathrm{HCl}$ & & & & \\
\hline
\end{tabular}


Table 3 Summary of the five methods and properties of the final product for the tested methods and the organic extraction method.

\begin{tabular}{|c|c|c|c|c|c|c|}
\hline Method & 1 & 2 & 3 & 4 & 5 & Organic extraction \\
\hline \multicolumn{7}{|l|}{ Conditions } \\
\hline Column 1 & AG 1 & AG 1 & AG 1 & AG 1 & AG 1 & - \\
\hline Solution modification & $1 \mathrm{M} \mathrm{NaCl}$ & - & $1 \mathrm{M} \mathrm{NaCl}$ & - & - & - \\
\hline Column 2 & Sephadex G25 & Chelex 100 & Chelex 100 & Chelex 100 & Chelex 100 & - \\
\hline Solution modification & - & - & - & $1 \mathrm{M} \mathrm{NaCl}$ & $1 \mathrm{M} \mathrm{NaCl}$ & - \\
\hline Column 3 & AG 50 & Sephadex G25 & Sephadex G25 & Sephadex G25 & Sephadex G25 & - \\
\hline Column 4 & - & - & - & - & AG 50 & - \\
\hline \multicolumn{7}{|l|}{ Results } \\
\hline$\%$ recovery of $\mathrm{Ge}$ & 45.6 & 87.8 & 82.5 & 43.2 & 41.5 & $\sim 85$ \\
\hline$\% \mathrm{Ge}$ in $\mathrm{BVs} 1 \& 2^{\mathrm{a}}$ & 96.1 & 99.4 & 97.2 & 93.2 & 96.7 & \\
\hline Mass Ge $(\mu \mathrm{g})$ & 275.5 & 530.3 & 498.3 & 260.9 & 250.6 & $80-525$ \\
\hline Conc. Ga (ppm) & 0.13 & 15 & 1.7 & 1.6 & 0.1 & 41.1 \\
\hline Mass Ga $(\mu \mathrm{g})$ & 1.5 & 183 & 20 & 19 & 1.4 & $80-525$ \\
\hline$\%$ Ga remain & 0.0002 & 0.0244 & 0.0027 & 0.0025 & 0.0002 & --- \\
\hline Conc. Zn (ppm) & ND & ND & ND & ND & ND & Up to 10.2 \\
\hline Conc. Co (ppm) & 0.13 & 0.24 & 3.13 & 0.062 & ND & ND \\
\hline Mass Co $(\mu \mathrm{g})$ & 1.6 & 2.9 & 37.6 & 0.75 & 0 & ND \\
\hline$\%$ Co Remain & 0.32 & 0.58 & 7.52 & 0.15 & 0 & ND \\
\hline
\end{tabular}

ND: not detectable. ICP-OES LLOQ (lower limit of quantification): $0.1 \mathrm{ppm}(\mathrm{Zn})$, and $0.005 \mathrm{ppm}(\mathrm{Co})$. In methods 1-5 the final volume of $\mathrm{Ge}$ in the $0.1 \mathrm{M} \mathrm{HCl}$ was $12 \mathrm{~mL}$. The \% recovery or remaining is calculated from the sum off all $\mathrm{HCl}$ fractions. a $=\% \mathrm{Ge}$ in BVs 1 \& 2 was calculated based on the total Ge eluted in the $\mathrm{HCl}$ fractions.

following properties were compared: \% Ge recovered, concentration of $\mathrm{Ga}$ and $\mathrm{Co}$, and the mass $(\mu \mathrm{g})$ of $\mathrm{Ge}$, $\mathrm{Ga}, \mathrm{Co}$ and $\mathrm{Zn}$. Ge recovery: In methods 2 and 3 the percent Ge recovered was 87 and $82 \%$ as compared to $40-45 \%$ for methods 1,4 and 5 . Fractionation of $\mathrm{HCl}$ : The final concentration of Ge needs to be high in order to meet activity concentration requirements. The percent of eluted $\mathrm{Ge}$ in the $\mathrm{HCl}$ fractions was greater than $96 \%$ in bed volumes $1 \& 2$ for methods $1-3$, and 5 , and was $93 \%$ for method 4 . This indicates a narrow band of Ge on the Sephadex G25 column that is rapidly eluted from the column with $0.1 \mathrm{M} \mathrm{HCl}$. It is worth noting that the high concentrations of $\mathrm{Ge}$ in bed volumes $1 \& 2$ would translate into high radioactivity concentrations, and concentration step of the final product would not be needed. This is extremely important because germanium chloride is volatile making it difficult to concentrate the product safely. Alternatively, eluting with $0.1 \mathrm{M}$ nitric acid could be problematic, as a white solid was observed when the solution was evaporated. Evaporating high specific activity ${ }^{68} \mathrm{Ge}$ in nitric acid solution could lead to irrecoverable losses to the glassware [7]. Ga remaining: The organic extraction method produced Ga concentration in the final product from 30-50 ppm. In methods 1-5 the final product (Ge in $12 \mathrm{~mL}$ of the eluted $\mathrm{HCl}$ ) would have a $\mathrm{Ga}$ concentration of $15 \mathrm{ppm}$ for method 2, and 1.6-1.7 ppm for methods 3 and 4, and 0.11-0.13 ppm for methods 1 and 5. The AG50 column used in methods 1 and 5 reduced the mass of $\mathrm{Ga}$ in the product by a factor of 10 over methods 3 and 4 which did not use the column. Influence of $\mathrm{NaCl}$ : Methods 1, 3-5 used Sephadex with $\mathrm{NaCl}$ and the concentration of Ga was reduced when compared to method 2 which did not use $\mathrm{NaCl}$. Method 2 does not use $\mathrm{NaCl}$ in either Sephadex or Chelex 100 steps and has a 10 fold higher concentration of Ga than similar methods $3 \& 4$ that use $\mathrm{NaCl}$. A study varying the concentration of $\mathrm{NaCl}$ from 0.1-1.5 indicated no correlation between $\mathrm{NaCl}$ concentration and $\mathrm{Ge}$ and Co concentration in the final product. However, a linear correlation was present between the 
concentration of $\mathrm{Ga}$ in the final product and the concentration of $\mathrm{NaCl}$ used in the separation $(\mathrm{y}=2.3 \mathrm{x}$ $+0.6, \mathrm{R}^{2}=0.88$ ). Although this is an interesting finding the final concentration of $\mathrm{Ga}$ in the $\mathrm{HCl}$ fractions of all the methods was below the concentrations obtained by the organic extraction method. Method 3 looks the most promising for removal of $\mathrm{Ga}$ and recovery of $\mathrm{Ge}$, on the other hand the amount of $\mathrm{Co}$ in the final product is much higher than the other methods. $\mathrm{Zn}$ remaining: The amount of $\mathrm{Zn}$ in the $\mathrm{HCl}$ fractions for methods 1-5 was below the functional limit of detection (1 ppm) for the ICP-OES, so the first step in the separation has to be the dilution of the sample to $1.5 \mathrm{M} \mathrm{HCl}$ and removal of $\mathrm{Zn}$ with an AG 1 column. Co remaining: The percentage of $\mathrm{Co}$ remaining out of the initial $500 \mu \mathrm{g}$ was: $0.32 \%$ (method 1), $0.58 \%$ (method 2), 7.5\% (method 3$)$, and $0.15 \%$ (method 4 ). The concentration of Co remaining after method 5 was below the LLOQ for the ICP-OES.

\section{Conclusions}

This research evaluates a basic solvent system with various resins for the purification of germanium. Five different methods were evaluated for the purification of Ge from Ga, Co and Zn. Methods 2 and 3 have the best properties for the purification of Ge and will be evaluated further with irradiated $\mathrm{Ga}$ targets to determine if either can be used in the production of ${ }^{68} \mathrm{Ge}$. The high concentration of germanium in the eluted $\mathrm{HCl}$ fractions (bed volumes 1 and 2) of the Sephadex G25 column is ideal for the purification of ${ }^{68} \mathrm{Ge}$.

\section{Acknowledgments}

This study was supported by funding provided by the Department of Energy, Office of Nuclear Physics, subprogram Isotope Development and Production for Research and Applications.

\section{References}

[1] Breeman, W., Jong, M. D., Blois, E. D., Bernard, B. F., Konijnenberg, M., and Krennin, E. 2005. "Radiolabelling DOTA-peptides with ${ }^{68}$ Ga." Eur. J. Nucl. Med. Mol. Imaging 32 (4): 478-85.

[2] Morgenstern, A., Bruchertseife, F., Apostolidis, C., Giesel, F., Mier, M., Haberkor, U., et al. 2012. "Synthesis of ${ }^{213}$ Bi-DOTATOC for Peptide Receptor Alpha-therapy of GEP-NET Patients Refractory to Beta Therapy." In SNM's 59th Annual Meeting: 455.

[3] Meinkin, G. E., Kurczak, S., Mausner, L. F., Kolsky, K. L., and Srivastava, S. C. 2005. "Production of High Specific Activity ${ }^{68} \mathrm{Ge}$ at Brookhaven National Laboratory." J. Radioanal. Nucl. Chem. 263 (2): 553-7.

[4] FDA Documents: Guidance for Industry Q3C Impurities: Residual Solvents 1997.

[5] FDA Guidance for Industry Q3C-Tables and lists 2003.

[6] Isotope Production Group, Brookhaven National Laboratory, Batch Records of Germanium production. Upton, NY, Number of batches $=21$, from $2 / 2008$ to 7/2011.

[7] Mirzadeh, S., and Lambrecht, R. M. 1996. "Radiochemistry of Germanium." J. Radioanal. Nucl. Chem. 202 (1): 7-102.

[8] Lewis, J. 1961. The Radiochemistry of Aluminum and Gallium. National Academy of Sciences-National Research Council Report.

[9] Fitzsimmons, J. M., and Mausner, L. 2015. "Development of a Production Scale Purification of ${ }^{68} \mathrm{Ge}$ from Irradiated Gallium Metal." Radiochimica Acta 103 (2): 117-23.

[10] Harada, A., Tarutani, T., and Yoshimura, K. 1988. "Spectrophotometric Determination of Germanium in Rocks after Selective Adsorption on Sephadex Gel." Analytica Chim. Acta 209: 333-8.

[11] Wood, S. A., and Samson, I. M. 2006. "The Aqueous Geochemistry of Gallium, Germanium, Indium and Scandium." Ore Geology Reviews 28 (1): 57-102.

[12] Kraus, K., and Nelson, F. 1995. Ion Exchange Chromatography, edited by Walton, H. F. Dowden, Hutchinson \& Ross, Inc., Vol. 1, 161-70. 